\title{
Pulling an all-nighter: current trends of college students' use of adderall
}

\begin{abstract}
Stimulant medication has, for numerous years, been the pharmacological treatment of choice for children and adults with Attention- Deficit/Hyperactivity Disorder (ADHD) and Narcolepsy. For individuals with one or more of these disorders and who take Adderall, the main effect of the drug is to attain a normal ability to focus on tasks without becoming easily distracted. The primary purpose of this study was to investigate the increasing popularity of Adderall among college students. The authors conducted an investigation of one hundred and forty one college students at a Midwest college. Results demonstrated that the following students have experimented with Adderall as a study aid: $51 \%$ of seniors, $31 \%$ of juniors, $16 \%$ of sophomores, and $19 \%$ of freshman. The investigators also found that males were significantly more likely to use Adderall as compared to female students. There were no significant differences between athletes and non-athletes, and, "Greek" and "non-Greek" students in terms of Adderall use.
\end{abstract}

Keywords: adderall, misuse, study aid, college
Volume 3 Issue I - 2016

\author{
Jean Kiernan,' Carolyn Reid,' Panayiotis \\ Zavos $^{3}$ \\ 'Department of Health Sciences, Georgetown College, USA \\ 'Eastern Kentucky University, USA \\ ${ }^{3}$ Andrology Institute of America, USA
}

Correspondence: Panayiotis Zavos, Director \& Chief of Andrology, Andrology Institute of America, Professor of Reproductive Medicine, University of Kentucky, Lexington, Kentucky, USA, Tel I- 859-278-6806, Fax I-859-278-6906, Email zavos@zavos.org

Received: September 06, 2016 | Published: November 16 , 2016

\section{Introduction}

Most students are familiar with the phrase "pulling an all-nighter" when it comes to studying for college exams and/or graduate work. However, both professors and students are often unaware of how much this phrase's meaning has evolved over the years. Today, college students are not just using caffeine to stay alert, but are taking the prescription drug Adderall to enhance their studying abilities. Adderall has become a popular drug of choice for college students preparing to take an exam, deliver a presentation, or even to write term papers. The culture of academia is challenging, competitive, and often life-altering for many students. It reflects the general cultural fixation on efficiency, competence, and competition. In order to be successful many students often feel immense pressure to maintain a strong Grade Point Average. As a solution to this intense and competitive environment, students are increasingly turning to "study" drugs such as Adderall. Among the general population, the use of stimulant medications such as Adderall seems to be on the rise. Recent reports ${ }^{1}$ indicate that parents now visit doctors to insist upon obtaining Adderall for their children, with the expectation that it will improve their child's grades and performance. Flory et al., ${ }^{2}$ report that the number of prescriptions for ADHD medications for youth increased $46 \%$ between 2002 and 2010. Many studies indicate that this trend continues with college aged students, although the number misusing Adderall or other stimulants is difficult to determine. McCabe et al. ${ }^{3}$ found a lifetime use rate of $8 \%$ while Advokat et al. ${ }^{4}$ found that $43 \%$ misused Adderall. Other studies indicate as many as one in four college misused Adderall medications. ${ }^{5}$ A recent article in the New York Times (2015) reports that the mindset among college students is that Adderall is a legitimate way to get through the stressors of academic and social life. Some college students view the drug as no different as a strong cup of espresso. In fact, research has documented that students who viewed stimulant medication misuse as not harmful were 10 imes more likely to have used stimulant medications in the past year than those who perceived stimulant medication as harmful. ${ }^{6}$
Adderall is a Schedule II substance that was put on the market to treat Attention Deficit/Hyperactivity Disorder, Attention Deficit Disorder, and Narcolepsy. For individuals with one or more of these disorders and who take Adderall, the main effect of the drug is to attain a normal ability to focus on tasks without becoming easily distracted. Individuals who use Adderall without a prescription tend to feel supercharged and invincible. ${ }^{7}$ Schedule II drugs include the following criteria:

i. The drug or other substance has a high potential for abuse;

ii. The drug or other substance has a currently accepted medical use in treatment in the United States or a currently accepted medical use with severe restrictions;

iii. Abuse of the drug or other substances may lead to severe psychological or physical dependence. ${ }^{7}$ Other examples of Schedule II drugs are cocaine, morphine, oxycodone, methadone, and opium.

Adderall, or amphetamine-dextroamphetamine, was first marketed in the 1960s as the diet pill of choice. It is made up of a mixture of four amphetamine salts that stimulate the brain. The drug worked as a stimulant to assist metabolism and dieting efforts. Adderall is a stimulant, specifically a cocktail of amphetamine salts. Adderall boosts levels of two neurotransmitters in the brain, dopamine and norepinephrine. Dopamine is thought to play a key role in memory and the onset of addictive behaviors. Dopamine has many functions in the brain, including important roles in behavior and cognition, voluntary movement, motivation, punishment and reward, inhibition of prolactin production (involved in lactation and sexual gratification), sleep, mood, attention, working memory, and learning, while norepinephrine has been linked to alertness, arousal, and influences on the reward system. ${ }^{8}$ Adderall is a highly addictive drug, and college students are taking the risk to experiment with it in order to stay focused and earn a higher grade. It is no secret to college students that Adderall is considered better than Cliffs Notes, copies of previous exams, or study sessions when it comes to preparing for an exam or 
presentation or writing a research thesis or manuscript. These benefits of Adderall have been demonstrated in both children and adults. Users are able to complete cognitive tasks efficiently whereas without the drug they may not be able to. However research on misusers of stimulant medication indicates that using stimulant medication may have no academic benefit. Rabiner et al., ${ }^{9}$ found that the GPA for nonusers was 3.28 compared to a GPA of 3.16 for non-users.

\section{Materials and methods}

\section{Sample}

The population of interest for this study is college students. The population that is accessible to this study consists of students in a small liberal arts college in the Midwest. The sample was obtained from students who agreed to complete a survey at a distinct location on campus. The study resulted in a sample size of 141 participants over the two-day course of the study. Study participants were classified as either Freshmen, Sophomores, Juniors or Seniors. The majority of participants $(65 \%)$ were female. The study sample is representative of the population of interest and the results could be applicable to other small college populations.

\section{Measures}

The measures used in this study were that of a brief questionnaire and consisted of the following questions:

i. What year of school?

ii. What is your sex?

iii. Greek or independent?

iv. Student athlete vs. non-athlete?

v. Have you ever taken Adderall, without a prescription, as a study aid?

vi. Did Adderall help you study?

vii. Would you take Adderall as a study aid again?

The instrument was administered on two separate, consecutive days (See Appendix A).

\section{Design}

The population of this study was a convenience sample of undergraduate college students who were entering the school cafeteria. The college is a small liberal arts college (enrollment 1800) located in the Midwest USA. Given that this study was interested in understanding how often Adderall was used as a study aid, using this convenience sample is a strength, however, as with all convenient samples, an unknown portion of the population is excluded and have no chance of being included therefore results may not accurately reflect all students at this small Midwest college.

\section{Procedure}

As participants arrived at the school cafeteria they were asked if they were willing to complete a survey about their use of Adderall. Participation was at gratis, entirely voluntary and students could choose not to take the survey. By taking the survey, students thereby gave their informed consent. The researchers gave each participant a survey and explained that they may cease participation at any time. Student responses to the survey were anonymous and no other personal or identifiable information was collected. The researcher then asked the participants to please read the directions carefully and fill out the survey to the best of their ability. Upon completion, the participants were then asked if they would be willing to answer a few more questions which were recorded by the researchers. Students were then asked if they had any questions for the researcher and were thanked for their cooperation. Surveys were placed in a marked box, collected and stored in a secure location. Data was analyzed using Mini-tab.

\section{Results}

The primary purpose of this investigation was to examine the number of college students who have taken un-prescribed Adderall, as a study aid. Of the 141 students sampled, $30 \%(n=43)$ used Adderall without a prescription.

Adderall use by class rank: The class of students that seemed to consume the most Adderall as a study drug was seniors. Fifty-one percent of seniors surveyed $(n=19)$ had tried un-prescribed Adderall once over their four years. Thirty-one percent of juniors $(n=14)$ had tried Adderall compared to sixteen percent $(n=3)$ of sophomores and nineteen percent of freshman $(\mathrm{n}=7)$. Seniors exhibited significantly $(\mathrm{p} \leq .05)$ more Adderall use than other classifications. The Pearson correlation of Class and Adderall Use $r=-0.307 / \mathrm{P}-$ Value $=0.01$ (Table $1)$.

Table I Adderall Use by class rank

\begin{tabular}{lll}
\hline Class rank & Sample (N) & $\begin{array}{l}\text { Tried adderall } \\
\text { (Unprescribed ) }\end{array}$ \\
\hline Freshmen (Year One) & 39 & $19 \%(n=7)$ \\
Sophomores & 19 & $16 \%(n=3)$ \\
Juniors & 44 & $31 \%(n=14)$ \\
Seniors & 38 & $51 \%(n=19)$
\end{tabular}

Adderall and reuse: When asked if they would use prescribed Adderall again, nearly $96 \%$ of students responded "yes". ${ }^{10}$ Students claimed that "kiddie coke" is the best thing that entered their academic career. The majority of the subjects would reuse Adderall if they were Table 2.

Table 2 Adderall use and reuse by class rank

\begin{tabular}{llll}
\hline Class rank & Sample & $\begin{array}{l}\text { Tried adderall } \\
\text { unprescribed }\end{array}$ & $\begin{array}{l}\text { Would reuse } \\
\text { adderall }\end{array}$ \\
\hline First Year & 39 & $19 \%(n=7)$ & $83 \%$ \\
Sophomores & 19 & $16 \%(n=3)$ & $67 \%$ \\
Juniors & 44 & $31 \%(n=14)$ & $86 \%$ \\
Seniors & 38 & $51 \%(n=19)$ & $78 \%$ \\
\hline
\end{tabular}

Adderall use by sex: Males were significantly more likely (41\%, $\mathrm{n}=20)$ to use Adderall as compared to $25 \%(\mathrm{n}=23)$ of female students. Further, $78 \%$ of female students indicated that they would reuse Adderall and $85 \%$ of males indicated that they would reuse Adderall. Pearson correlation of Sex and Adderall Use $=r=-0.164 / P-$ Value $=0.053$ (Figure 1).

Adderall use and greek life: Twenty-two Independent subjects had tried un-prescribed Adderall compared to twenty-one subjects who 
were affiliated with Greek life. The relationship between un-prescribed use of Adderall and Greek affiliation was not statistically significant $(\mathrm{p}=.089)$. The Pearson correlation of Affiliation and Adderall Use, $r$ value $=0.015 / \mathrm{P}-$ Value $=0.89$ (Figure 2$)$.

\section{Sex: Adderall Use and Possible Reuse}

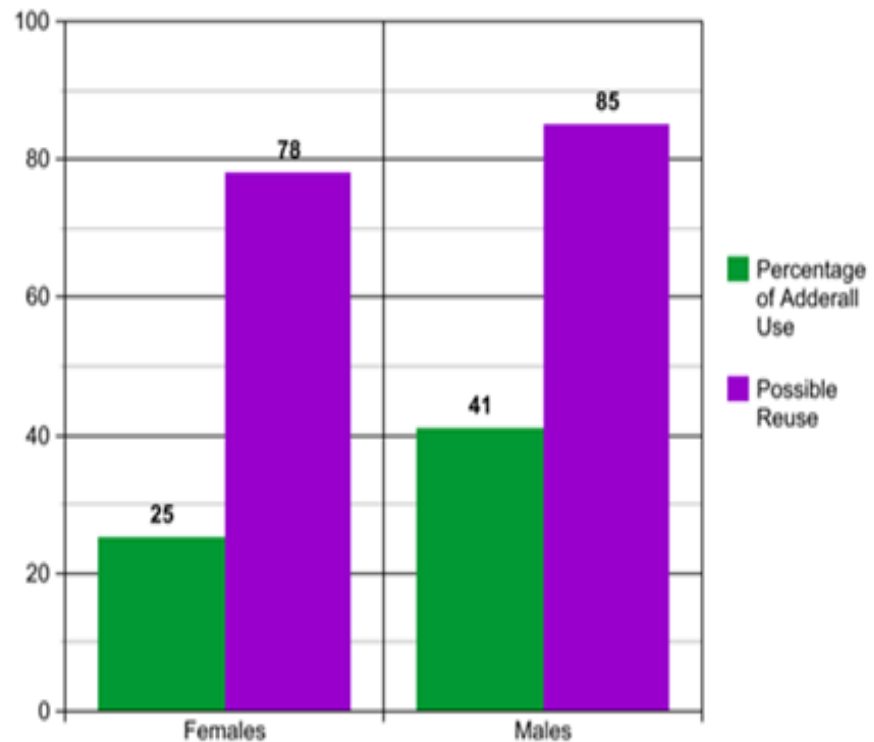

Figure I Percentage of adderall use and reuse according to sex.

Sex: Adderall Use and Possible Reuse

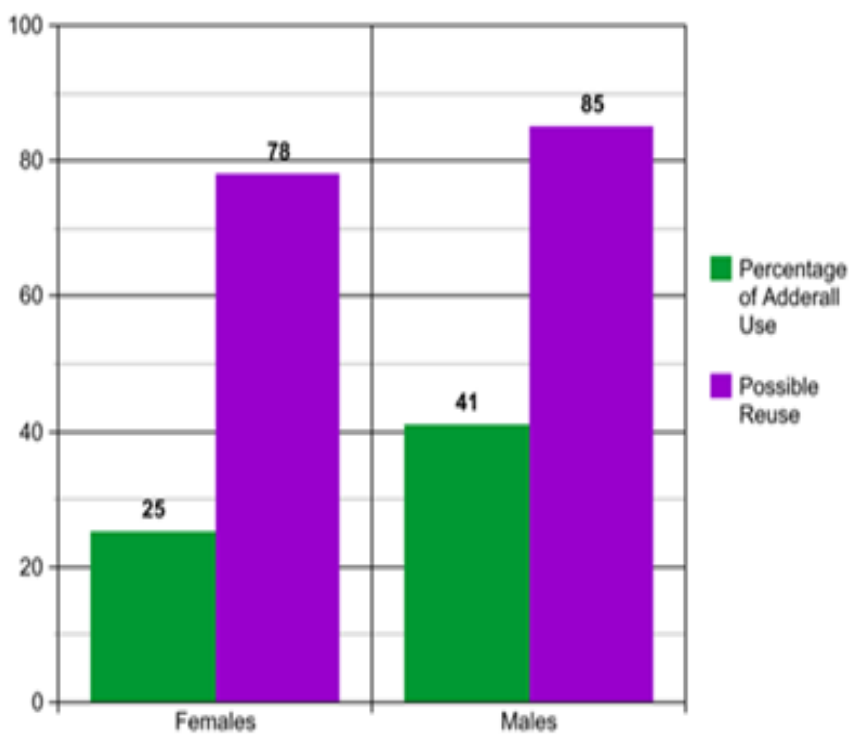

Figure 2 Adderall Use by numbers and percentage for greek life.

Adderall use and athletic participation: The relationship between taking un-prescribed Adderall and athletic participation demonstrated no statistical significance $(\mathrm{p}>.05)$. Of the forty-three subjects who admitted to taking un-prescribed Adderall, nineteen were athletes and twenty four were non-athletes. The Pearson correlation among these two variables was as follows: $r=0.12 ; p$ value $=0.13$ (Figure 3 ).

Following completion of the survey, students were asked open ended questions regarding their use of Adderall. The majority of the subjects in this study had only positive comments regarding Adderall. It was interesting, however, that only $10 \%$ of the subjects knew the actual ingredients in Adderall. The majority of the subjects (70\%) believed that Adderall was safe because it was a controlled substance produced under medical guidelines.

Individual interviews after this study included the following comments about Adderall:

a) "The drug is amazing! I can concentrate all night and not have to worry about getting my work finished. I'd take it every day if I could get a prescription."

b) "Most of my friend's take it and I don't have a chance to compete with them if I don't do the same."

c) "I loved the drug for about 5hours and then I got really tired and irritable. I'm not sure if I would take it again."

d) "The drug is miraculous! I would work the night shift, as a bouncer, come home at 4a.m., study for 5hours and then go to class ready to debate and learn! I love the stuff! ---I can get you some if you want."

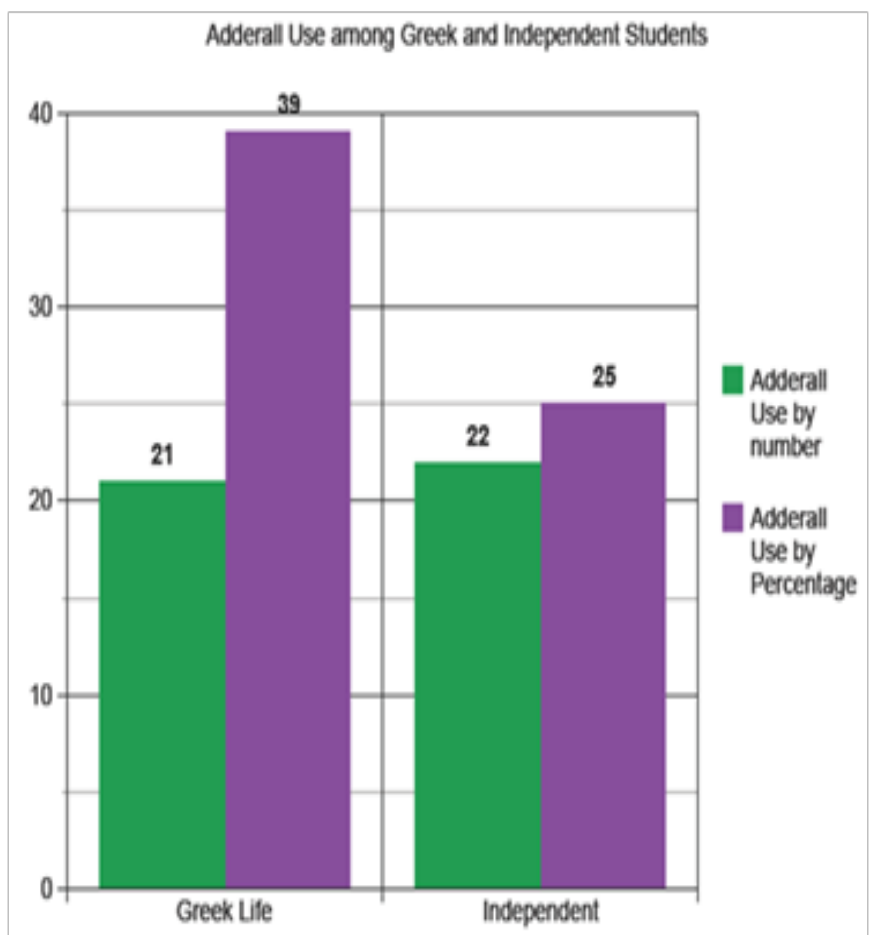

Figure 3 Adderall use among athletes/non-athletes.

\section{Discussion}

Despite the potential negative health consequences, the use of Adderall is alive on college campuses across the country. The study drug trade on college campuses speaks to the pressure that students face on a regular basis. Not only would many students experiment with Adderall as a study aid, they would reuse the drug if needed. Studies on past year use among college students show a range of $5.3 \%{ }^{9}$ to $35.3 \%{ }^{11}$ For this study, the $30 \%$ is on the high-end for past year usage indicating that even on small campuses the number 
of students using is incredibly high. Studies examining gender and Adderall misuse have found that males are significantly more likely to misuse Adderall. ${ }^{8}$ This study confirms previous research indicating that males are more likely to misuse Adderall. This also points to a need to reach out to males with education and awareness on the dangers of Adderall misuse. Most of the literature seems to indicate that students involved in Greek life are more likely to misuse stimulant medication compared to non-Greek students. ${ }^{8}$ This study did not show a significant difference between Greek and non-Greek students. Although there was not a significant relationship between Adderall use and Greek affiliation $(p=0.089)$, there was a fourteen percent difference between possible reuse for subjects in Greek life versus Independent subjects. Students associated with Greek life were fourteen times more likely to reuse Adderall as a study aid compared to Independent students. ${ }^{12}$

It is possible that the 'norms' within Greek life and the number of 'health education' workshops addressing issues such as Stimulant Abuse at smaller campuses provides a protective factor for students in Greek life. It is possible that the discovery process of uncovering one's strengths and weaknesses may get lost through Adderall misuse. The idea of learning from one's failures may be diminished. Even being able to decipher one's career may become unclear because of false illusions of success stemming from Adderall use. ${ }^{13}$ If the Adderall Revolution continues it may be very hard to predict future success of our college students, especially if they enter into fields that were chosen due to the Adderall effect rather than the natural process. Part of the college experience is learning innovative and healthy ways to cope with life's stressors. Each person has his/her academic limits, and these, in the long run, help us grow and learn. Learning to do the best that one can to balance his/her limits with strengths is simply a part of life. Students should have many opportunities to learn about their academic strengths and weaknesses. Evaluating strengths and weaknesses is an essential part of life and the academic process. In doing this students may have the opportunity to improve their weaknesses and preserve their strengths.

\section{Acknowledgements}

None.

\section{Conflict of interest}

The author declares no conflict of interest.

\section{References}

1. Snow K. More people using Adderall to get an edge. The Cycle. 2015.

2. Flory K, Payne R, Benson K. Misuse of prescription stimulant medication among college students: Summary of the research literature and clinical recommendations. Journal of Clinical Outcomes Management. 2014;21(12):559-568.

3. McCabe SE, Teter CJ, Boyd CJ. Medical use, illicit use and diversion of prescription stimulant medication. J Psychoactive Drugs. 2006;38(1):43-56.

4. Advokat CD, Guidry D, Martino L. Licit and illicit use of medications for attention-deficit hyperactivity disorder in undergraduate college students. J Am Coll Health. 2008;56(6):601-606.

5. McDaniel A, Hale K. College prescription drug study. USA: The Ohio State University; 2015. p. 1-22.

6. Arria AM, Caldeira KM, Vincent KB, et al. Perceived harmfulness predicts nonmedical use of prescription drugs among college students: Interactions with sensation-seeking. Prev Sci. 2008;9(3):191-201.

7. Patterson E. Adderall abuse on the rise among young adults. USA: John Hopkins Magazine; 2016.

8. DeSantis AD, Webb EM, Noar SM. Illicit use of prescription ADHD medications on a college campus: a multimethodological approach. $J$ Am Coll Health. 2008;57(3):315-324.

9. Rabiner DL, Anastopoulos AD, Costello EJ, et al. Motives and perceived consequences of nonmedical ADHD medication use by college students: Are students treating themselves for attention problems? J Atten Disord. 2009;13(3):259-270.

10. Kiernan J. Adderall, College students and health. Presentation at the International Health and Wellness Convention. USA: Berkeley University; 2014.

11. Low KG, Gendaszek A. Stimulant abuse in college undergraduates. Psychology, Health and Medicine. 2002;7:283-287.

12. Dussault CL, Weyandt LL. An examination of prescription stimulant misuse and psychological variables among sorority and fraternity college populations. J Atten Disord. 2013;17(2):87-97.

13. Herman E. Using Adderall to get ahead, not to fight ADHD. New York Times, USA; 2015. 